\title{
Relações raciais digitais: um estudo sobre as formas de expressão da intolerância racial no Facebook
}

\author{
Sheyla Fernandes, Marcikele Nascimento, Alanda Pereira e Erika Melo e Kathleen Carlos \\ sheyla.fernandes@ip.com.br; nascimentomarcikele@gmail.com; alanda-maria@outlook.com; \\ erikamanuellasm@gmail.com; kathleenlimapsi@gmail.com \\ Universidade Federal de Alagoas, Brasil
}

DOI: 10.17013/risti.38.79-91

\begin{abstract}
Resumo: Esta pesquisa tem por objetivo analisar a expressão da intolerância racial no Facebook. Foram selecionados 5 sítios abertos, entre páginas e grupos, no site Facebook por meio do descritor "Racismo" e termos correlatos. Destes, foram coletados os comentários das 5 postagens mais relevantes. Os dados foram transcritos de modo a comporem um corpus textual que foi analisado a partir do software Iramuteq. Os resultados apresentaram 3 eixos principais: o primeiro reporta o reconhecimento do racismo; o segundo remete à importância da representatividade negra; o terceiro aborda a existência de uma democracia racial. Considerou-se relevante discutir a forma pela qual as crenças raciais são expostas no Facebook, reproduzindo manifestações de intolerância, mas também de militância, gerando um discurso que demonstra diferentes faces da segregação racial nesse contexto.
\end{abstract}

Palavras-chave: Racismo; Crenças; Facebook

\section{Digital race relations: a study about forms of expression of racual intolerance on Facebook}

\begin{abstract}
This research aims to analyze the expression of racial intolerance on Facebook. 5 open sites were selected, between pages and groups, on the Facebook site through the descriptor "Racism" and related terms. Of these, comments were collected from the 5 most relevant posts. The data were transcribed in order to compose a textual corpus that was analyzed using the Iramuteq software. The results presented 3 main axes: the first reports the recognition of racism; the second refers to the importance of black representation; the third addresses the existence of racial democracy. It was considered relevant to discuss the way in which racial beliefs are exposed on Facebook, reproducing expressions of intolerance, but also of militancy, generating a discourse that demonstrates different faces of racial segregation in this context.
\end{abstract}

Keywords: Racism; Beliefs; Facebook 


\section{Introdução}

Casos de racismo nas redes sociais online (RSO) são abundantemente frequentes de modo a surgirem quase 18 milhões de produtos a partir de uma busca na plataforma Google com o descritor "racismo nas redes sociais".

Considerando dois sítios eletrônicos, o Espaço vital independente (www.espacovital. com) e o Portal Geledés (www.geledes.org.br), duas notícias nos chamaram a atenção. Em novembro de 2019, no Espaço vital, a matéria reporta quatro casos de racismo, salientando que não são os únicos, de grande destaque no Brasil para discutir a alarmante expansão desse fenômeno. O primeiro caso apresentado ocorreu no mês de maio de 2019. Um ex-árbitro de futebol brasileiro revelou por meio de relatos diversos episódios de racismo que sofreu ao longo de sua carreira no esporte. Já no ano anterior, foi publicada a foto de uma jovem negra que ganhou repercussão por expor que sua falta de emprego estaria vinculada às características de seu cabelo. Em 2015 e 2016, respectivamente, uma repórter da principal difusora de telecomunicações do Brasil, assim como uma atriz da mesma emissora, ambas negras, foram vítimas de intolerância virtual (Meura, 2019).

A segunda notícia, publicada no ano de 2014 no Portal Geledés, menciona a rede social Facebook como palco para promoção de intolerância racial aberta. Trata-se de um tipo nocivo de violência que aparece explícita e sem receio de ferir o artigo $5^{\circ}$ da Constituição Federal. Tal artigo considera a prática de racismo como crime inafiançável, não obstante, diferentes páginas publicam incontáveis ofensas dirigidas aos negros com demasiada frequência. Em algumas dessas postagens é recorrente a apologia ao nazismo por meio de frases que incentivam o ódio aos negros e outras minorias. Algumas dessas páginas chegam a atingir mais de 186 mil curtidas (Rezende, 2014).

Com o advento e grande proporção de acesso das RSO, as práticas de racismo adquirem o poder de articular milhões de pessoas rapidamente demonstrando a presença de um racismo à espreita de uma oportunidade para se apresentar (Silva, 2019).

Levando em conta que as redes sociais atualmente constituem a crescente estratégia de comunicação instantânea no mundo (Cano \& Roch, 2019; Teixeira \& Azevedo, 2011), entende-se como um desafio administrar os conteúdos expressos em larga escala nas páginas do Facebook e em outras mídias sociais (Stein, Nodari \& Salvagni, 2018). A falta de controle do que é veiculado anuncia a fragilidade de contenção de violência gratuita que se traduz em um campo fértil para a exteriorização de atitudes intolerantes. Esse conteúdo odioso propagado nas RSO apresenta potencial danoso em diferentes aspectos da vida que vão além do ciberespaço. Diferentes estudos demonstram que expressões de intolerância e preconceito são cada vez mais frequentes nesses ambientes (Canedo et al., 2016; Dantas e Abreu, 2016). Valendo-se da proteção da identidade oferecida pelo espaço digital, postagens de comentários e opiniões que se refiram pejorativamente à cor, etnia, à orientação sexual, por exemplo, são bastante comuns (Dantas e Abreu, 2016).

$\mathrm{Na}$ literatura interessada no racismo, as explicações desse fenômeno passam de explicações de bases fatuais, de julgamentos prévios e apressados, para bases emocionais, isentas de causalidade real (Allport, 1954), e posteriormente para bases 
sociais que se estabelecem a partir das lutas ideológicas pelo poder social entre os grupos (Camino et al., 2004).

Deste modo, o racismo, em uma das mais antigas definições, aparece como um produto eminente das generalizações falhas e inflexíveis de um grupo em relação a outro ou seus membros individualmente em função de sua pertença, podendo ser expresso ou não (ver Allport, 1954).

Jones (1972) argumenta que o racismo é um processo natural que ocorre entre os grupos a partir da aquisição de significações negativas das características físicas e culturais de um conjunto de pessoas dentro de uma sociedade heterogênea, e este processo ocorre por meio da acentuação das características positivas do endogrupo e das negativas do exogrupo.

Três níveis distintos, sequenciais e complementares aportam as formas de expressão do racismo: o racismo individual, o racismo institucional e o racismo cultural. O primeiro, o racismo individual, é muito semelhante ao preconceito racial, visto que sugere a crença na superioridade da raça do endogrupo com relação ao exogrupo, assim como as sanções comportamentais derivadas desta relação. Como exemplos do racismo individual, Jones cita os testes padronizados como critérios de admissão de estudantes em certas escolas e universidades. Os negros certamente possuem um nível de instrução desfavorecido e por isto apresentam rendimentos inferiores, tendo em vista principalmente a condição de desigualdade social existente entre brancos e negros. Assim, a utilização destes testes seria a situação per si de discriminação racial (Jones, 1972).

O racismo institucional, tipo mais “insidioso e debilitante" está relacionado à manipulação consciente de instituições com o interesse de atingir objetivos racistas. Este tipo tem dois sentidos, um sentido que o remete a extensão do racismo individual, logo, seu princípio segue a ideia de manutenção de vantagem racista individual por meio de instituições, e um sentido que o remete à condição de subproduto de práticas institucionais que atuam de forma a limitar a liberdade e os direitos igualitários em função da raça, sendo a raça tida como inferior a prejudicada.

O racismo cultural, por sua vez, ocorre na relação dos níveis individual e institucional da suposta superioridade cultural de uma raça em relação a outra (Jones, 1972). Assim, o racismo cultural está associado à significação inferior atribuída à raça e à cultura de um povo, sendo raça e cultura dois padrões entendidos como fatores bastante correlacionados e, portanto, a base sistemática de tratamento inferiorizante (Jones, 1972).

Com efeito, as relações raciais são produto de um conjunto de fatores que integram a história, a cultura e demais elementos imbricados em um nível psicossocial. Nesses termos, a condição de inferiorização dos negros decorre desde o período de escravidão, dado que reflete diretamente na desigualdade social (Cruz, 2017). Paralelo a esse produto, um fenômeno que emerge é o branqueamento. O branqueamento tanto remete à miscigenação da população, gerando pessoas menos enegrecidos, com atributos característicos da raça negra menos aparentes, como refere também uma pressão cultural para que as pessoas negras neguem a si mesmas através da adesão aos atributos fenotípicos, culturais e demais características das pessoas brancas (Maia \& Zamorra, 2018). 
Deste modo, compreender alguns componentes das relações raciais no contexto brasileiro implica, sobretudo, considerar a singularidade deste fenômeno em uma nação genuinamente marcada pela mistura de raças.

$\mathrm{O}$ argumento de que as relações raciais em países onde a segregação não ocorre tanto pelo viés das diferenças culturais, como é o caso do Brasil, gerou um termo peculiar para referir o racismo: racismo cordial. Em um estudo encomendado pelo Datafolha, cujo objetivo consistiu em analisar as relações raciais brasileiras junto a uma amostra representativa do Brasil, Turra e Venturi (1995) demonstraram que apenas 10\% dos brasileiros investigados se consideram racistas, no entanto, um mais de $50 \%$ dos respondentes concordam com frases do tipo "Negro bom é negro de alma branca" ou "Se Deus fez raças diferentes, é para que elas não se misturem". Turra e Venturi (1995) denominaram esse tipo de racismo brasileiro de "racismo cordial" em virtude da cordialidade com que se nega ser racista neste país onde, na própria opinião dos participantes, o racismo é notório (Lima \& Vala, 2004).

Estudos posteriores buscam dar suporte a este modelo de racismo (Camino et al. 2004; Fernandes, 2011; Fernandes, 2018), apresentando definições que remetem o racismo cordial ao nível das relações interpessoais, pautado, sobretudo, em formas indiretas de expressar a antipatia contra negros.

Partindo do pressuposto de que o racismo ainda predomina na contemporaneidade sob diferentes faces (Fernandes \& Pereira, 2019), e que o branqueamento e a idealização de uma igualdade racial brasileira se constituem como assuntos fundamentais para o entendimento das relações raciais nesse contexto, refletir sobre as estratégias de manutenção do processo de inclusão-exclusiva do negro na sociedade brasileira (Silva, 2017) possui um propósito reiteradamente atual. Assim, esta pesquisa tem por objetivo analisar a expressão da intolerância racial em um ambiente virtual marcado pela livre expressão e por abundante acesso comunicativo. Por se tratar de uma das redes sociais mais acessadas do mundo (Kemp, 2018), o Facebook foi o locus selecionado para realizar as análises. Essa pesquisa aborda uma extensão do ensaio apresentado por Fernandes et al (2020) sobre racismo e crenças raciais digitais junto ao Congresso Ibero-Americano em investigação qualitativa.

\section{Metodologia}

Realizou-se uma busca na RSO Facebook (http://facebook.com.br/) com a finalidade de selecionar 5 sítios, dentre grupos e páginas, que contivessem assuntos pertinentes às relações raciais. Para operacionalizar a pesquisa foram utilizados os descritores "racismo", "negritude" e "preconceito racial” no espaço de busca da RSO. Posteriormente, os sítios que (1) abordavam assuntos relativos às relações raciais, (2) apresentavam livre acesso e (3) dispunham de um quantitativo mínimo de mil membros seguidores, foram indicados como ambientes que comportavam os dados de interesse para essa investigação. A partir dessa seleção, os comentários das 5 postagens mais relevantes (visualizadas, compartilhadas e/ou curtidas) no período de busca foram coletados. A recolha dos dados ocorreu entre $1^{\circ}$ de outubro e 31 de dezembro de 2017. 
Para processar os dados, o produto textual de todos os comentários foi transcrito com auxílio do OpenOffice Writer (Afonso, 2010). Como não faziam parte do objetivo da investigação, dados referentes aos autores dos comentários foram suprimidos.

Em seguida, realizou-se uma revisão cuidadosa do texto sendo excluídos quaisquer produtos que não tratassem das relações raciais. O resultado final dessa revisão constituiu um corpus textual que foi explorado com o auxílio do software Iramuteq (Interface de $\mathrm{R}$ pour les Analyses Multidimensionnelles de Textes et de Questionnaires) (Ratinaud, 2009). Para proceder às análises duas técnicas foram utilizadas, a análise da nuvem de palavras e análise de similitude. O corpus apresentou, 221 segmentos de texto (ST) e 7 967 palavras (número de ocorrências).

A nuvem de palavras apresenta uma representação gráfica do material textual que agrupa as palavras em função de sua frequência e possibilita uma visualização clara da saliência dos elementos principais do corpus. Quanto maiores e mais centralizadas, as palavras apresentam maior frequência. A análise de similitude, por sua vez, permite uma estruturação ponderada do corpus a partir da co-ocorrência de palavras em segmentos de textos (ST). Por se ancorar na teoria dos grafos, os resultados da análise de similitude são representados graficamente revelando as relações entre as formas linguísticas do produto textual sendo possível o rastreio do discurso produzido sobre o assunto alvo da pesquisa (Camargo \& Justo, 2013; Salviati, 2017; Souza et al., 2020).

\section{Resultados}

Ao analisar o corpus denominado aqui de crenças sobre as relações raciais no Facebook, a nuvem de palavras (Figura 1) demonstra que as palavras relativas às relações raciais mais relevantes foram: Negro, branco, pessoa, racismo e preconceito. Tais palavras se ancoram em comentários que giram em torno de uma rejeição ao racismo, como por exemplo nos trechos:; "Gostaria de saber em qual o parágrafo do Código Penal se basearam essas pessoas para constrangerem e humilharem uma criança negra"; "inocentes sofrendo por causa desse preconceito burro...”. Por outro lado, nota-se uma evidente demonstração de hostilidade evidente no campo cibernético relativamente às pessoas Negras e ao problema do racismo: "Não ligo para racismo pois ele não enche minha barriga...” e “... o negro sempre foi cidadão de segunda classe”. Foram observados também discursos que negam a existência de problemas nas relações raciais: "O racismo está em quantificar a quantidade de negros em determinado ramo de atividade, bem como cotas de negros em universidades como se o negro fosse inferior ao branco."; "Não estou conseguindo perceber preconceito".

Tendo observado as palavras mais proeminentes do corpus e seus respectivos ST, o que permitiu de forma suscinta apreender alguns tópicos que embasam os discursos produzidos nos sítios investigados, analisou-se em que medida acontece a conexão entre esses discursos.

A Figura 2 apresenta a árvore de co-ocorrências que emerge como resultado da análise de similitude. Grosso modo, a aproximação entre os vocábulos é representada pela espessura das linhas das ramificações da árvore (Nascimento, Cajavilca \& Santos, 2019). Para sentenças mais próximas, tem-se linhas de maior espessura. 


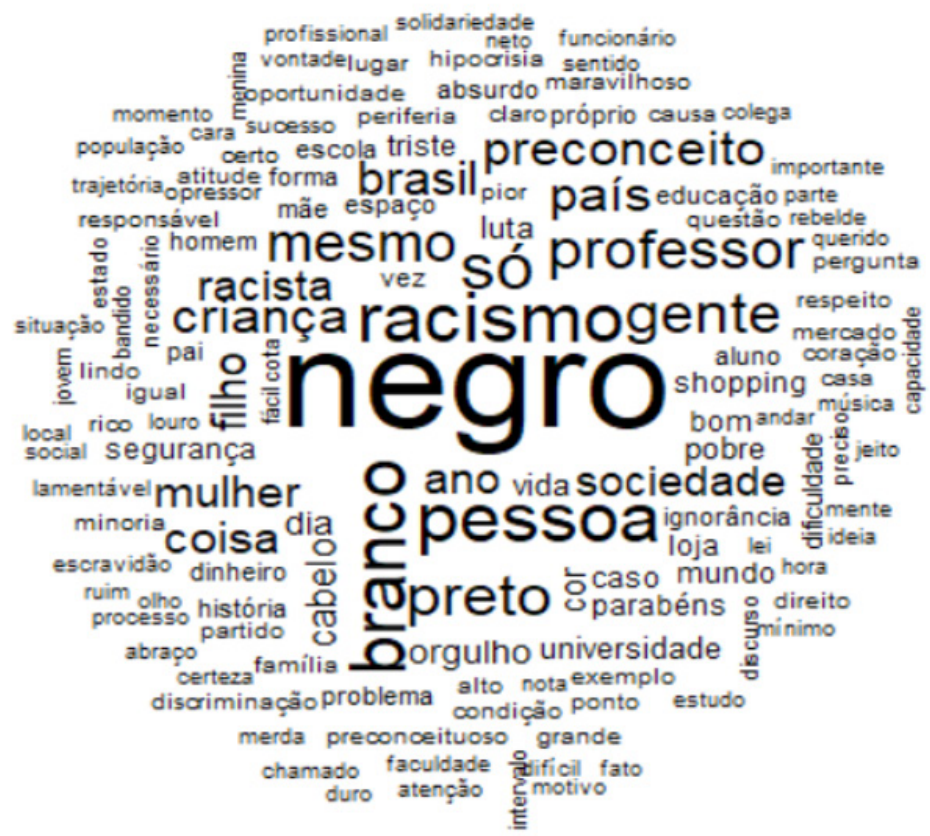

Figura 1 - Nuvem de palavras das crenças sobre as relações raciais no Facebook

Pode-se observar que as palavras destacadas na árvore compreendem as já mencionadas na Figura 1, no entanto, para além de revelar sua importância nos discursos, é possível reparar a estreita vinculação entre elas. A palavra "negros" expressa um dos vértices mais acentuados da árvore com a palavra "brancos", indicando em que sentido ambas as palavras aparecem conjugadas: "Os brancos que estão no poder. Querem que continue assim no Brasil. Nos mantendo excluídos. (...) a certeza que tenho é que um branco tem um universo de oportunidades, enquanto ao negro, é preciso muito esforço, muito estudo e muito empenho. (...) Temos mais de 50 porcento de negros na sociedade brasileira. Quando as pessoas dão depoimento que em toda a sua vida escolar $e$ acadêmica tiveram menos de 1 porcento de professores negros, você não pode dar outro nome além de racismo. Se causa estranheza ou é motivo de ser noticiado um juiz, um cônsul, um ministro negro, é porque a sociedade ainda não é igualitária." Estes trechos refletem comentários relacionados à forma como os indivíduos representam e patenteiam o racismo. Fica evidente a percepção da falta de harmonia nas relações raciais existente no país. Reconhece-se o peso de assimetria nessas relações que se mantém e se expõem abertamente nos contextos digitais.

Nessa direção, comentários acerca das expressões racistas que resultam em sentimentos devastadores na vida das vítimas também são elucidados: "O primeiro racismo percebido e lembrado por mim, foi na escola. Aos 7 anos. Se toda esta desgraça fosse coisa da nossa cabeça seria fácil resolver, mas foi a Branquitude quem inventou a ética 


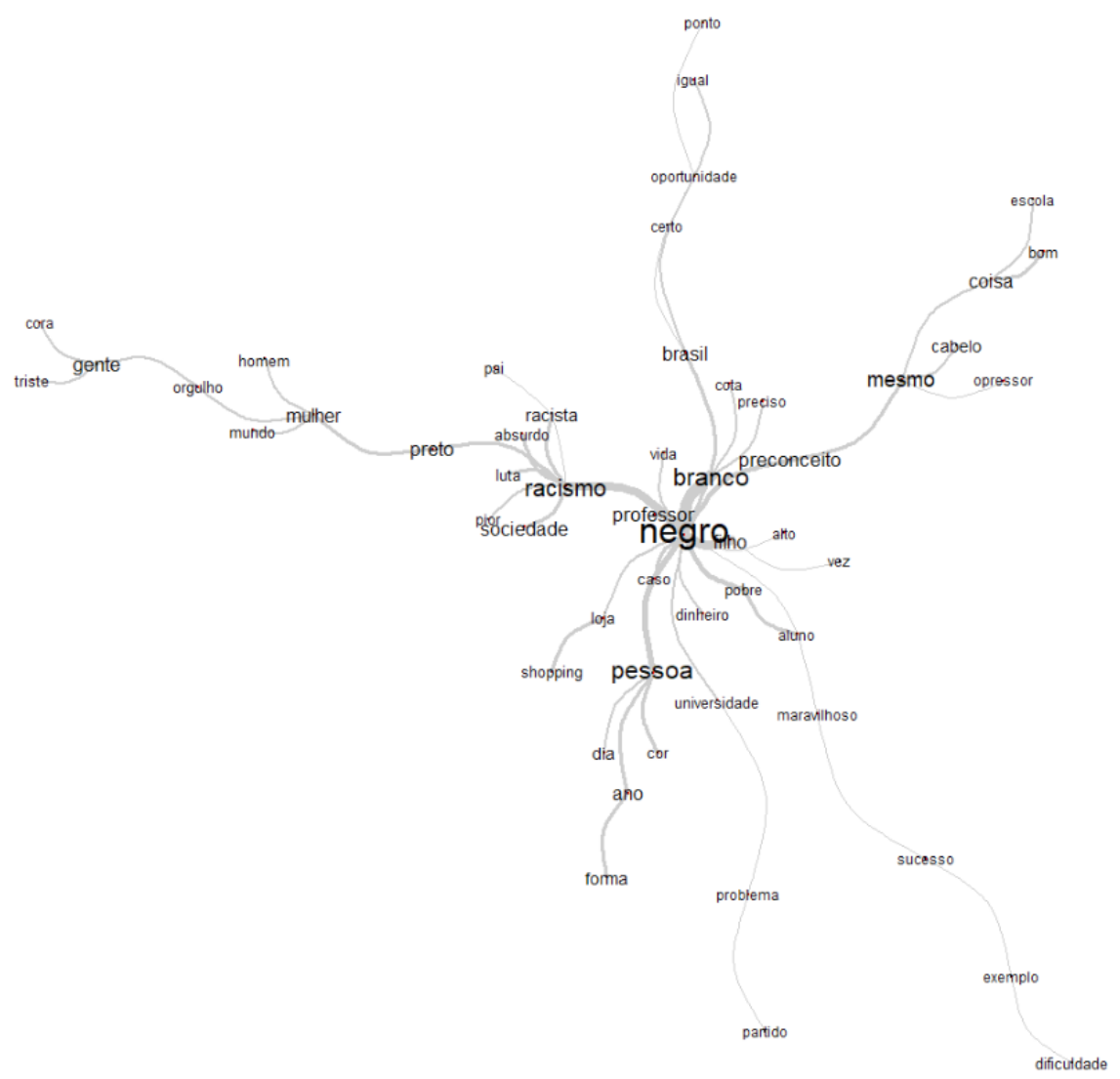

Figura 2 - Árvore de co-ocorrências sobre as relações raciais no Facebook

do racismo. (...) Eu quero ser líder em conjunto com minhas irmãs e irmãos pretos e pretas! Nós temos muita coisa para consertar! (...) Lamentável. Quanto mais eu leio, mas eu me enlouqueço. Li tanta asneira que não sei nem por onde começar. Senti uma dor de cabeça lendo isso, como pode existir pessoas assim? Cada dia que passa desisto mais da humanidade. (...) "convivo com preconceito desde sempre porque me casei com homem negro. (...) Sofro preconceitos diários nesse bairro, em inúmeras lojas”.

Muito embora esses discursos estejam presententes e acentuadamente marcados nesses sítios de internet, alguns discursos seguem caminho contrário gerando uma força que impulsiona a deslegitimação da existência do racismo. Com base no descredenciamento de tudo que é relativo aos negros, seja no que concerne à expressão hostil de racismo, seja na negação deste, alguns comentários que relativizam sua existência se centram em torno das palavras "negro", "racismo" e "branco": "Aquela velha história de não sou racista, mas. (...) O racismo é uma hipocrisia. (...) Fui ofendido pelo fato de ser branco, 
o Filme Pantera negra agride os brancos, como posso recorrer a essa ofensa? (...) como se o negro fosse inferior ao branco. Tem muito negro rico e muito branco pobre.”.

Um contraponto que pode ser apreciado, considerando-se os eixos anteriormente revelados, trata-se da militância negra. O tom de enfrentamento ao racismo demonstrado nos ST desse eixo assinala a importância das lutas dos negros enquanto ferramenta de coibição do racismo. Essa configuração provoca uma crescente reconfiguração na demarcação do lugar do negro na sociedade. Torna-se possível apreender o papel fundamental do reconhecimento de avanços individuais e coletivos para a ressignificação desse sentimento de pertença grupal que, embora ramificados de forma mais tênue à palavra "racismo", é possível de se observar nas palavras "luta”, "preto", "orgulho", por exemplo: "Vai ter quilombola na universidade e formado sim. Estamos caminhando em rumo a mais essa conquista. Gente linda e emponderada. Orgulho define. (...) "sinto tanto orgulho das mulheres pretas guerreiras que me precederam e abriram caminho para que eu pudesse me construir. (...) gente que continua lutando e gente que luta e lutou apoiando de todas as maneiras possíveis a causa negra”.

Fazendo referência à militância, é possível perceber de forma adicional uma relação entre as palavras "negro" e "pessoa". Os discursos aqui se coadunam ao enfrentamento do racismo, mas elucidam a questão da representatividade e empoderamento: "O dia que Hollywood cedeu à beleza verdadeiramente negra. (...) Separar as pessoas por cor nunca foi algo tão importante que precisasse ser quantificado, pelo menos pra mim. (...) No ano de 2017 me vi diante desta identidade forte que é a nossa. Consigo compreender exatamente o que é ser negra e conquistar o nosso espaço. Na universidade da qual pertenço existem muitas ações de aceitação da identidade e cultura negra, e assim percebo o peso que é ser uma universitária negra. (...) Somos gente negra. Temos cor, temos nome, temos vontade. (...) Com isso me orgulho de carregar a essência de sangue dos meus ancestrais africanos e indígenas.

Por fim, o último eixo que se destaca parte da relação entre as palavras "brancos" e "preconceito". Desta ramificação alguns ST reforçam o poder do debate instantâneo que ocorre nas RSO a despeito do cruzamento de diferentes pontos de vista. Percebe-se o descontentamento e desacordo quanto à inferiorização da identidade negra, ao passo que que se circunscreve em forma de resposta à indignação um tipo de retaliação à condição sofrida: "A criança chegou em casa chorando, porque ouviu que seu cabelo não foi lavado, por ser duro. Triste ver como um local destinado à educação, fomenta o preconceito contra crianças, pois o estrago é maior do que se pensa, além do óbvio, acabar com a auto estima da criança, ainda entuba nas outras crianças que devem rejeitar quem possui cabelo crespo. (...) Fogo nos racistas. Literalmente! A sociedade nos deve políticas de restituição pelo que nos foi roubado pelos brancos. (...) Opressor nunca vai respeitar o povo preto nessa posição, ou povo preto se deita e morre depois de servir ou se levanta, em posição ereta e existe em igualdade no espaço! (...) $O$ acirramento do preconceito, da intolerância, acontece quando avançamos na luta."

\section{Discussão}

Os resultados aqui expostos podem ser discutidos à luz de alguns aspectos tanto da perspectiva do racismo cordial (Turra \& Venturi, 1995), como das reflexões oriundas das 
premissas do branqueamento (Maia \& Zamorra, 2018). A condição em que a sociedade brasileira se estabeleceu desde sua origem, coloca como atributo fundamental, inclusive, agregado de valor, a mistura de raças. Deste modo, é essencial que ao discutir o racismo brasileiro, eleve-se em primeiro lugar a singularidade das relações raciais de seu povo. Esse fenômeno denominado de racismo cordial como sendo tipicamente um fenômeno brasileiro, remete a uma cordialidade forjada em que ao mesmo tempo se nega ser racista, enquanto o racismo é evidente (Fernandes, 2011; Turra \& Venturi, 1995). Sobre essa consideração, os resultados permitem pelo menos duas reflexões centrais: (1) ainda é restrita a conscientização do racismo enquanto um problema das relações raciais brasileiras; (2) apesar da tentativa de deslegitimização da luta antirracista que ocorre nos sítios eletrônicos, uma força combativa vem ganhando espaço e adeptos em prol da luta pela dignidade e representatividade das pessoas negras.

Pode-se ponderar que o racismo atravessa o campo físico e se expressa de modo violento nas redes sociais. Fato alarmante, uma vez que o maior alcance de propagação de ideias e discussões, aliados à isenção de responsabilidade comuns aos atos que ocorrem na vida digital, tornam essa expressão de intolerância mais frequente e flagrante, no entanto, suas consequências são tão danosas quanto as expressões tradicionais (Fernandes et al., 2020; Silva, 2019).

Além disso, essas particularidades do racismo à brasileira (Fernandes \& Pereira, 2019), conduzem a um processo de tentativa de anulação da causa dos negros, até mesmo da construção de uma identidade negra positiva que, por conseguinte, repercute na ideologia do branqueamento enquanto padrão nacional (Panta \& Pallisser, 2017). Como forma de enfrentar essa contingência, as pessoas negras produzem manejos para a negação da sua africanidade, disfarçando traços característicos de sua raça com vias a aproximar sua aparência do padrão branco (Santana \& Santos, 2016; Silva, 2017). Assumir a identidade negra no Brasil parece se tratar de um processo bastante complexo, dado que, mesmo se tratando de um povo miscigenado, o padrão positivo é eurocêntrico. Malafaia (2018) explana que essa construção gerou um conjunto de denominações para se referir a uma pessoa negra, como moreno, moreno cor de canela ou termos correlatos, de modo a sustentarem que se referir a alguém como negro fosse indicativo de ofensa.

Assegurar uma identidade positiva para as pessoas é extremamente importante para sua constituição enquanto sujeito. Um modelo que possibilite inspiração e reconhecimento em busca da subversão da negatividade da identidade negra se coloca como imperativo para uma mudança nas relações raciais (Gomes, 2012; Souza, 1983). Os discursos produzidos pelos atores sociais analisados nessa pesquisa indicam que a representatividade no Facebook, assim como em outros veículos comunicacionais digitais, podem implicar potencialmente em ferramentas de anulação da dinâmica de inferiorização social da população negra, constituindo-se como poderosos recursos geradores de novas configurações.

\section{Conclusões}

A partir dos resultados discutidos nessa investigação, é possível evidenciar que a intolerância racial no contexto brasileiro tem sido frequentemente expressa nas redes sociais, e de forma mais restrita, através do Facebook, ambiente onde os dados foram 
coletados. Esse dado não significa, no entanto, que o racismo cotidiano está em declínio, mas que a rápida difusão, o fácil acesso e a popularidade do Facebook o colocam como locus ideal para sua disseminação. Portanto, faz-se necessário que mais estudos sejam desenvolvidos no sentido ampliar o conhecimento sobre a violência digital.

Importa salientar também, que há uma força contrária, que se estabelece basilar para os movimentos negros, claramente crescente militando em favor da cidadania plena da comunidade negra. Atesta-se, então, que se as RSO são utilizadas frequentemente como campo de intolerâncias das mais diversas, embora seja um desafio constante, esses ambientes podem em vem sendo utilizadas também como espaço de resistência.

Por se tratar de um fenômeno que apresenta diferentes facetas, no que se refere à sua natureza e formas de expressão (Lima \& Vala, 2004), investigar os elementos que giram em torno dessa modalidade despreocupada e irresponsável de expressão de racismo, consiste em um campo vasto ainda a ser percorrido, sendo necessário abranger suas dimensões política, psicossocial e cultural.

Para finalizar, faz-se relevante indicar algumas limitações do presente estudo que, mesmo respondendo ao objetivo central, podem fornecer alguns caminhos para estudos posteriores. $\mathrm{O}$ corpus textual utilizado como fonte de informações não permite traçar considerações a despeito de todo o espaço virtual nacional, uma vez que a única RSO investigada foi o Facebook. Outro aspecto que limita as conclusões apresentadas se refere a designação dos descritores utilizados. Possivelmente a ampliação dos descritores conjuntamente ao incremento de demais RSO podem promover resultados mais abrangentes. Estudos dessa natureza parecem frutíferos no sentido de preencher lacunas na literatura da área sobre o preconceito digital. Espera-se que investigações futuras tomem como base as considerações aqui apresentadas e compartilhem informações sobre sítios diversificados, uma vez que ainda são escassos esses tipos estudos.

\section{Referências}

Afonso, A. (2010). Manual de Tecnologias da Informação e Comunicação e OpenOffice. org. Disponível em http://www.adrianoafonso.net/files/manuais/manual_ tic_2ed_nivelbase_anjaf.pdf

Allport, G. W. (1954). The nature of prejudice. Cambridge: Addison-Wesley.

Bernardino, J. (2002). Ação afirmativa e a rediscussão do mito da democracia racial no Brasil. Estudos AfroAsiáticos, 24(2), 247-273.

Camargo, B. V., \& Justo, A. M. (2013). IRAMUTEQ: Um software gratuito para análise de dados textuais. Temas em Psicologia, 21, 513-518. Camargo, B. V., \& Justo, A. M. (2016). Tutorial para uso do software IRAMUTEQ. Disponível em http://www.iramuteq.org/documentation/fichiers/Tutorial\%20IRaMuTeQ\%20 em\%20portugues_17.03.2016.p df

Canedo, H. S.; De Amorim, M. Al.; Da Silva, L. L. (2016). Crimes de ódio na imprensa brasileira: um estudo dos discursos sobre o racismo em notícias jornalísticas. Temática, v. 12, n. 2. 
Cano M., Jeimy J., \& Rocha, Alvaro. (2019). Ciberseguridad y ciberdefensa: Retos y perspectivas en un mundo digital. RISTI - Revista Ibérica de Sistemas e Tecnologias de Informação, (32), vii-ix. https://dx.doi.org/10.17013/risti.32.o

Cruz, A. M. (2017). História e cultura afro-brasileira: uma análise da implementação da Lei 10.639/o3 no Colégio Cataratas do Iguaçu. UNILA.

Dantas, W. M.; Abreu, G. (2016). Homofobia não: violência simbólica e preconceito em uma comunidade ativista do Facebook. Temática, v. 12, n. 6.

Fernandes, S. C. S. (2011). Crenças Raciais e Infra-humanização: uma análise psicossocial do preconceito contra negros. Universidade Federal da Bahia.

Fernandes, S. C. S. (2018). Preconceito de cor e racismo: aspectos teóricos e metodológicos. Ed. 1: Edufal.

Fernandes, S. C., \& Pereira, M. E. (2019). Atitudes étnico-raciais: elaboração e evidências de validade de uma medida do racismo à brasileira. Psico, 5O(4), 28624.

Fernandes, S., Nascimento, M., Pereira, A., Melo, E., \& Carlos, K. (2020). Relações raciais no facebook: análise de comentários acerca de conteúdos raciais digitais. In F. Freitas, I. Pinho, A. I. Rodrigues, B. M. Faria, \& A. P. Costa (Eds.), Investigação Qualitativa em Ciências Sociais: avanços e desafios (volume 4) - NTQR (1 a, pp. 317-329). Oliveira de Azeméis - Aveiro - PORTUGAL: Ludomedia - Building Knowledge. https://doi.org/10.36367/ntqr.4.2020.317-329

França, D. X., \& Monteiro, M. B. (2015). Identidade racial e preferência em crianças brasileiras de cinco a dez anos. Psicologia, 16(2), 293-323.

Gomes, N. L. (2012). Movimento negro e educação: ressignificando e politizando a raça. Educação \& Sociedade, 33(120), 727-744.

Guimarães, A. S. A. (2004). Preconceito de cor e racismo no Brasil. Revista de Antropologia, São Paulo, 47(1), 9-43.

Kemp, S. Special Reports Digital In 2018: world's internet users pass the 4 billion mark. [S. 1.]. Disponível em https://wearesocial.com/blog/2018/o1/global-digitalreport-2018.

Kleina, M. C. N. (2016). Curtir, Comentar ou Compartilhar? As Potencialidades do Facebook Como Ferramenta de Mobilização Digital. Em Debate, Belo Horizonte, 8(4), 33-40.

Lima, M. E. O., \& Vala, J. (2004). Sucesso social, branqueamento e racismo. Psicologia: teoria e pesquisa, 2O(1), 11-19.

Maia, K. S., \& Zamora, M. H. N. (2018). O Brasil e a lógica racial: do branqueamento à produção de subjetividade do racismo. Psicologia Clínica, 3o(2), 265-286.

Malafaia, E. D. S. (2018). A importância da representatividade negra na construção de identificação em crianças negras a partir de literatura infanto-juvenil negra. X COPENE: Congresso Brasileiro de Pesquisadores Negros. Uberlândia - MG. 
Martins, A. C. L.(2019). Discurso de ódio em redes sociais e reconhecimento do outro: o caso M. Revista Direito GV, São Paulo, 15(1), 1-30. Myers, D. G. (2014). Psicologia Social: AMGH Editora.

Meura, K. (2019). Racismo nas redes sociais. Disponível em https://www.espacovital. com.br/publicacao-37069-racismo-nas-redes-sociais. Acessado em 14/10/2020.

Nascimento, T. C., Cajavilca, E. S. R., \& Santos, A. T. (2019). Sistematização de um Modelo de Prospecção Tecnológica com as Ferramentas Espacenet e Iramuteq: aplicação para banco de dados de patentes verdes do elemento fósforo. Cadernos de Prospecção, 12(3), 563.

Pacheco, L. C. (2011). Racismo cordial: manifestação da descriminalização racial à brasileira - o domínio público e privado. Revista de Psicologia, Fortaleza, 2(1), 137-144.

Panta, M., \& Pallisser, N. (2017). "Identidade nacional brasileira" versus "identidade negra”: reflexões sobre branqueamento, racismo e construções identitárias. Revista Espaço Acadêmico, 17(195), 116-127.

Pires, A. M. L. T. (2010). El prejuicio racial en Brasil: medidas comparativas. Psicologia Social, Florianópolis, 22(1), 32-42.

Ratinaud, P. (2009). IRAMUTEQ: Interface de R pour les Analyses Multidimensionnelles de Textes et de Questionnaires [Computer software]. Disponível em http://www.iramuteq.org

Rezende, C. (2014). Comissão de Igualdade Racial da OAB-RJ vai acionar MP para Facebook retirar páginas do ar. Disponível em https://www.geledes.org.br/ racismo-sem-limites-nas-redes-sociais/. Acessado em 14/10/2020.

Salviati, E. M. (2017). Manual do Aplicativo Iramuteq. Planaltina, DF. Santana, N. M. C.;

Santos, R. A. (2016). Projetos de modernidade: autoritarismo, eugenia e racismo no Brasil do século XX. Revista de Estudios Sociales, (58), 28-38.

Silva, T. M. G. S. (2017). O colorismo e suas bases históricas discriminatórias. Direito UNIFACS-Debate Virtual, (201), 1-19.

Silva, A. C. (2019). Vítima de racismo de brasileiros, jogadora francesa superou "fim do mundo”. Paris, 25 jun. 2019. Disponível em https://esporte.uol.com.br/futebol/ ultimas-noticias/2019/o6/25/vitima-de-racismo-debrasileiros-atleta-francesa-javenceu-fim-do-mundo.htm.

Silva, M. L. (2017) População-sacer e democracia racial no Brasil. Sociedade e Estado, 32(3), 593-620.

Souza, N. S. (1983). Tornar-se Negro: as vicissitudes da identidade do negro brasileiro em ascensão social. $2^{\mathrm{a}}$ edição. Rio de Janeiro. Editora graal.

Sousa, Y. S. O., Gondim, S. M. G., Carias, I. A., Batista, J. S., \& de Machado, K. C. M. (2020). O uso do software Iramuteq na análise de dados de entrevistas. Revista Pesquisas e Práticas Psicossociais, 15(2), 1-19. 
Stein, M., Nodari, C. H. \& Salvagni, J. (2018). Disseminação do ódio nas mídias sociais: análise da atuação do social media. Interações, Campo Grande, 19(1), 43-59.

Teixeira, Diogo, \& Azevedo, Isabel. (2011). Análise de opiniões expressas nas redes sociais. RISTI - Revista Ibérica de Sistemas e Tecnologias de Informação, (8), 53-65. Recuperado em 14 de outubro de 2020, de http://www.scielo.mec.pt/scielo. php?script=sci_arttext\&pid=S1646-98952011000200006\&lng=pt\&tlng=pt.

Turra, C. \& Venturi, G. (1995). Racismo cordial: a mais completa análise de preconceito de cor no Brasil. São Paulo: Ática. 